\title{
DE DIOSES Y PRINCESAS: MITOLOGÍA EN EL HARZREISE DE HEINRICH HEINE ${ }^{1}$
}

\author{
ANDREA SCHÄPERS \\ Universidad Pontificia Comillas \\ aschapers@comillas.edu \\ ORCID: 0000-0002-5166-0960
}

\section{RESUMEN}

En su relato Harzreise contenido en la colección Reisebilder, Heinrich Heine manda de viaje a su protagonista por una región emblemática en el centro de Alemania y recrea imágenes pertenecientes a mundos mágicos y míticos, el mundo de los dioses grecorromanos y el de las creencias populares que pueblan los bosques y las zonas rurales. A través de las vivencias diurnas y los sueños nocturnos del narrador nos hacemos partícipes de lo que le preocupa al joven autor y nos damos cuenta de que, finalmente, nos lleva siempre al terreno que le interesa en el fondo de su ser: el destino de Alemania en los tiempos de la Restauración.

PALABRAS CLAVE: Harzreise, Heinrich Heine, mitos románticos, naturaleza, espíritus elementales.

\section{OF GODS AND PRINCESSES: MYTHOLOGY IN HEINRICH HEINE'S HARZREISE}

\section{ABSTRACT}

In his narration Harzreise contained in the Reisebilder collection, Heinrich Heine sends his protagonist on a journey through an emblematic area in central Germany and recreates images belonging to magical and mythical worlds, the world of the Greco-Roman gods and that of popular beliefs in forests and rural areas. Through the narrator's daytime experiences and nighttime dreams we take part in the young author's concerns and realise that he always takes us to the terrain that interests him at the core of his being: the fate of Germany in the times of the Restoration.

KEYWORDS: Harzreise, Heinrich Heine, romantic myths, nature, elemental spirits.

\section{INTRODUCCIÓN}

El conjunto de la obra de Heine queda delimitado y caracterizado por dos eventos históricos: la restauración de los principados alemanes tras el Congreso de Viena en 1814-15 y la revolución burguesa de 1848-49, una época denominada por la historiografía Vormärz, el Premarzo. Con los dos términos, «Restauración» (es decir, regreso a los tiempos prerrevolucionarios) y «Revolución» (toma de poder político por parte de la burguesía), queda descrito

${ }^{1}$ Este artículo ha sido redactado bajo el amparo del proyecto de investigación AGLAYA. Estrategias de innovación en mitocrítica cultural (H2019/HUM-5714) en el seno del grupo de investigación INTRA perteneciente al Departamento de Traducción e Interpretación y Comunicación Multilingüe en la Universidad Pontificia Comillas. 
el carácter transitorio de esta época (Höhn 2004: 5). Mientras que la Antigua Alemania tradicional pervive en imágenes idílicas y sentimentalistas, el comienzo de la revolución industrial empieza a afectar a la estructura política y social del país.

La literatura de la época reacciona de forma muy diversa a estas condiciones histórico-sociales, marcadas por su simultaneidad del inmovilismo político y cambio social. Es un tiempo de grandes contradicciones que se manifiestan en el deseo de unificación nacional en oposición a una visión crítica de un sistema feudal arcaico. En los años comprendidos entre 1830 y 1850, la Joven Alemania (Junges Deutschland), un grupo de escritores progresistas, representados por Karl Gutzkow, Heinrich Laube y Ludolf Wienbarg, lucha por la libertad individual y se opone a la restauración política. Este grupo es prohibido por la Dieta Federal de Frankfurt en 1835, que incluía a Heine entre sus integrantes, a los que consideraban antialemanes y afines a Francia, además de anticristianos y libertinos. Heine vive las contradicciones de este tiempo de transición y crisis de forma muy consciente y reflexiona sobre las mismas en mayor medida que otros escritores de su época (Höhn 2004: 6). El inmovilismo político es el objetivo de su crítica más mordaz, a la vez que aplaude el nuevo dinamismo económico y social, aunque es también uno de los primeros en vislumbrar el alto precio que habría que pagar por ello.

\section{REISEBILDER Y HARZREISE}

Entre los años 1826 y 1831 Heine publica los Cuadros de Viaje, los Reisebilder. Como sugiere el título, se trata de impresiones de viajes y, de hecho, la mayoría de las obras incluidas en esa colección se inspiran en viajes reales emprendidos por el autor. Una excepción la representa Ideen. Das Buch Le Grand donde el marco de la ficción no es un viaje real, sino que el autor transforma una serie de recuerdos de la infancia vivida en Düsseldorf en una especie de viaje hacia su interior. En el mes de septiembre de 1824, Heine realiza un viaje a pie por la región montañosa del Harz en el centro de Alemania. Empieza en Gotinga, ciudad en la que está cursando en ese momento estudios de Derecho, pasando por Osterode, Clausthal-Zellerfeld y Goslar para emprender camino hacia el monte Brocken al que asciende el 19 de septiembre. A continuación, camina hacia Ilsenburg para después seguir viaje por Halle y Jena hasta Weimar, donde tiene lugar un breve encuentro con Goethe que Heine únicamente menciona en alguna carta a amigos. ${ }^{2}$ Regresa a Gotinga pasando por Erfurt, Wartburg y Kassel. Este viaje, en su trayecto de Gotinga a Ilsenburg, es el que retrata en el célebre Harzreise incluido en el primer tomo de Reisebilder. En 1825, antes de obtener el título de doctor en Derecho, se convierte al cristianismo, recibiendo

\footnotetext{
${ }^{2}$ Carta a Rudolf Christiani de 26.5.1825 (DHA 6: 605) en la que se muestra impresionado por la evidente vejez de Goethe.
} 
en el bautismo el nombre de Christian Johann Heinrich, siendo este último nombre el que adopta como autor literario. En 1825 y 1826 veranea en la isla Norderney en el Mar del Norte y deja plasmadas sus impresiones en Nordsee que comprende dos ciclos líricos y un tercer ciclo en prosa, incluidos en los tomos 1 y 2 de los Reisebilder. La serie italiana de la colección, es decir, Reise von München nach Genua, Die Bäder von Lucca y Die Stadt Lucca, transforma en ficción un extenso viaje que realiza el autor en los meses de agosto a diciembre de 1828 que le lleva por el norte de Italia saliendo de viaje desde Múnich pasando por Trento, Verona, Brescia y Milán hasta llegar a Génova. A continuación, viaja a la ciudad de Lucca, Baños de Lucca, Livorno y Florencia. Tras publicar el último tomo de los Reisebilder y ante la imposibilidad de asentarse profesionalmente en Alemania, en 1831 se establece en París como corresponsal para periódicos alemanes. Únicamente regresará a Alemania en dos ocasiones.

Al elegir el título de Reisebilder («retratos de viaje» o «cuadros de viaje»), Heine aparentemente se alinea con el género de la literatura de viajes que estaba muy de moda en la época. En una carta dirigida a Ludwig Robert el 4 de marzo de 1825, Heine comenta:

Das Hübscheste was ich unterdessen schrieb ist die Beschreibung einer 'Harzreise' die ich vorigen Herbst gemacht, eine Mischung von Naturschilderung, Witz, Poesie und Waschington Irvingscher Beobachtung. (DHA 6:526)

Se inspiró para ello en las descripciones poéticas subjetivas recogidas en Sentimental Journey Through France And Italy (1768) de Lawrence Sterne al que admiraba y en Bracebridge Or the Humorists (1823 en traducción alemana) del republicano americano Washington Irving (Kircher 2016: 96).

Heine emplea el título de Reisebilder para distanciarse de aquella literatura de viaje basada en hechos y experiencias auténticas y resalta el carácter de obra de ficción. Con la reminiscencia a las artes plásticas y la figura retórica de la metáfora acentúa el carácter artístico y la invención poética (Boerner 2003: 209).

El autor se caracteriza por un estilo vivaz, sorprendente, lleno de ironías y juegos de palabras. Sin embargo, también es denso, plagado de alusiones, referencias intertextuales y dobles sentidos, con lo cual, indudablemente, muestra su maestría en el manejo de la lengua, pero también parece dirigirse a un lector determinado que entienda y sepa desambiguar las referencias a otros textos literarios clásicos y de la época, las parodias literarias y constantes ironías. No hay que olvidar que este particular estilo indirecto, lleno de dobles significados, le permite camuflar sus ácidas críticas hacia las autoridades de la época $\mathrm{y}$, de esta forma, ofrece un menor campo de actuación a la censura. Además, al decidir publicar los Reisebilder en formato de libro y no en entregas periódicas como era habitual en la época, evitaba la censura previa que era 
obligatoria para escritos menos voluminosos y artículos de prensa. ${ }^{3}$ Dado que Heine había experimentado en escritos anteriores cambios y recortes por la censura, la publicación en libros le permitía incluir las obras íntegras y sin recorte. A pesar de todas las medidas preventivas, los textos incluidos en Reisebilder son vetados por la censura en muchas ocasiones. El Harzreise se prohíbe en Gotinga por su crítica hacia la ciudad y la universidad. Por el entusiasmo expresado hacia Napoleón y la mordaz crítica hacia la nobleza y la iglesia, el segundo tomo de los Reisebilder es prohibido en algunos estados federados. Y el último tomo se prohíbe en Prusia poco después de publicarse (Roth 1994: 564). No hay que olvidarse de que el ciclo italiano terminaba en este tomo con la exclamación programática: «Aux armes, citoyens!» (DHA 7: 205).

De las obras recopiladas en los cuatro tomos de Reisebilder, el Harzreise es la que más popularidad alcanzó. El relato comienza en Gotinga con las célebres frases:

Die Stadt Göttingen, berühmt durch ihre Würste und Universität, gehört dem Könige von Hannover und enthält 999 Feuerstellen, diverse Kirchen, eine Entbindungsanstalt, eine Sternwarte, einen Karzer, eine Bibliothek und einen Ratskeller, wo das Bier sehr gut ist. [...] Die Stadt selbst ist schön und gefällt einem am besten, wenn man sie mit dem Rücken ansieht. (DHA 6: 83)

En una secuencia de seis días y cinco noches, el narrador nos lleva de viaje por los montes del Harz. Las experiencias durante el día son procesadas en los sueños durante la noche cuando se unen también los miedos y deseos secretos del caminante. El primer trayecto empieza en Gotinga y termina en Osterode, donde pasa la noche. Durante la caminata, el narrador reflexiona acerca de la Universidad de Gotinga y sus habitantes y no deja «títere con cabeza». El tono que emplea es muy vivaz, divertido y rico en alusiones. Pero su crítica es también tan aguda y agresiva que la Universidad de Gotinga consigue prohibir la obra en su ciudad y en las bibliotecas municipales. Por la noche, regresa en sueños a la sala de Derecho de la biblioteca de Gotinga donde aparece Themis, la diosa de la justicia, acompañada por una horda bulliciosa y parlanchina de profesores de Gotinga. Al día siguiente, prosigue el viaje a Clausthal donde visita las minas de plata y describe la vida de la población minera. Esa noche tiene un sueño de carácter poético-erótico que termina en pesadilla. El tercer día, el narrador visita Goslar y recuerda los tiempos de los antiguos emperadores de Alemania. Esta noche, se le aparece en sueños el espíritu del fallecido Dr. Saul Ascher para demostrarle disertando en términos racionalistas que la razón es lo supremo y que los espíritus no existen. Prosigue el viaje de día y el narrador visita el castillo de Harzburg donde se cruza con un bien

\footnotetext{
${ }^{3}$ Por resolución de la Dieta Federal de Carlsbad de 1819, la censura queda establecida en todos los estados de la Confederación Germánica, con respecto a las publicaciones menores de 20 pliegos y los periódicos.
} 
alimentado vecino de Goslar con el que conversa sobre la utilidad de la naturaleza. El narrador se aloja en casa de un minero y el sueño de esta noche evoca un mundo de cuento de hadas mezclado con alusiones políticas. El sueño se relata en forma de poema que conforma la parte central de la obra. El quinto día narra el viaje hacia el Brocken, la mítica montaña del Blocksberg, cantada por Goethe en su Faust I. En la casa del Brocken, el narrador presencia una bacanal de estudiantes de ideología nacionalista y por la noche, vive otra pesadilla en la que se le aparecen nuevamente personajes de Gotinga. Amanece el sexto y último día y el narrador presencia juntamente con los demás huéspedes la salida del sol en el Brocken y emprende la bajada. Pasa por el valle del río Ilse y canta a la princesa del mismo nombre en un poema. El relato cierra con una especie de prólogo, aunque el texto correspondiente no lleva este título. La trama al final se sitúa en Hamburgo, posteriormente al viaje, un 1 de mayo, donde el narrador autobiográfico comenta en visión retrospectiva lo vivido y expone sus motivos literarios:

Die 'Harzreise' ist und bleibt Fragment, und die bunten Fäden, die so hübsch hineingesponnen sind, um sich im Ganzen harmonisch zu verschlingen, werden plötzlich, wie von der Schere der unerbittlichen Parze, abgeschnitten. Vielleicht verwebe ich sie weiter in künftigen Liedern, und was jetzt kärglich verschwiegen ist, wird alsdann vollauf gesagt. Am Ende kommt es auch auf eins heraus, wann und wo man etwas ausgesprochen hat, wenn man es nur überhaupt einmal ausspricht. Mögen die einzelnen Werke immerhin Fragmente bleiben, wenn sie nur in ihrer Vereinigung ein Ganzes bilden. Durch solche Vereinigung mag hier und da das Mangelhafte ergänzt, das Schroffe ausgeglichen und das Allzuherbe gemildert werden. (DHA 6: 134)

Liedtke (2008: 172) afirma que Heine nos lleva, no a un mundo de cuento de hadas, sino a su propia realidad, una época de pequeños y grandes cambios que se hacen patentes en muchos ámbitos: tanto en las minas como en las casas de los mineros o las ciudades, donde «las catedrales milenarias se mandan derruir y los tronos imperiales acaban confinados al desván» (García Adánez 2003: 61) y que tampoco pasan inadvertidos por el narrador. En raras ocasiones encuentra lo que anhela en el poema inicial, es decir, la soledad y el encuentro con la naturaleza pura:

Auf die Berge will ich steigen,

Wo die frommen Hütten stehen,

Wo die Brust sich frei erschließet,

Und die freien Lüfte wehen. (DHA 6: 83)

Al contrario, por doquiera que va el narrador, encuentra a personas de las más diversas procedencias sociales, lo que contribuye a recrear un ambiente, testimonio auténtico de la época.

No debemos confundir esta pluralidad de temas, motivos y figuras con una especie de arbitrariedad impresionista y no confundir la forma abierta de narración con la falta de forma (Liedtke 2008: 172). El Harzreise está compuesto 
de forma muy elaborada, a lo que contribuyen las intervenciones líricas con las que alternan los temas de la narración. En el centro se encuentra el gran poema «Auf dem Berge steht die Hütte...»:

Auf dem Berge steht die Hütte,

Wo der alte Bergmann wohnt;

Dorten rauscht die grüne Tanne,

Und erglänzt der goldne Mond. (DHA 6: 106)

Vestido en forma romántico de cuento de hadas, proclama el lema de los tiempos modernos:

Alle Menschen, gleichgeboren,

Sind ein adliges Geschlecht. (DHA 6: 109)

Como veíamos, la alternancia regular de día y noche, de vivencia real y sueño que transforma las experiencias, concede al texto una estructura novedosa para la novela de viaje como género literario. Lo mismo ocurre con las poesías intercaladas, que estructuran la trama.

\section{LA Mitología EN LA OBRA DE HeINE}

Heine sentía fascinación por el mundo mitológico y empleaba las figuras en su obra con frecuencia e intención poética. Se encuentran poblando toda su obra en prosa y verso. En el tratado teorético sobre la mitología popular nórdica y alemana, Elementargeister, publicado ya desde el exilio en Francia, en 1835, Heine describe un mundo mítico con cuentos y leyendas de la tradición germánica pagana. Las figuras que referencia son seres mágicos que habitan la tierra, el aire y el agua, enanos, duendes, elfos y sirenas, pero también alude a personajes mitificados como el emperador Federico Barbarroja o el Rey Arturo. Para ello recurre a fuentes como los cuentos de los hermanos Grimm, escritos de Paracelso sobre los espíritus elementales y a textos barrocos, como los de Johannes Praetorius, sobre la materia (Häntzschel 2007: 197-200). En la obra de Heine, estos espíritus paganos a menudo son secundados por dioses antiguos, como en el poema Los dioses de Grecia incluido en los ciclos líricos El Mar del Norte en su obra temprana, hasta Unterwelt en Nuevos Poemas y Der Apollogott en el Romancero. Pero los «espíritus elementales» y los dioses paganos no solo tienen justificación poética y estética, sino que forman una parte inseparable de su simbología política: El regreso de los dioses antiguos y nórdicos señaliza el anhelo por la liberación erótica y estética y su presencia en la obra se entiende como protesta (Höhn 2004: 362).

A Heine le interesan sobre todo los contenidos panteísticos de las antiguas religiones que han sido cubiertos y desplazados por los contenidos cristianos, pero que no han desaparecido del todo (Kortländer 2003: 301): 
Jene ältere Dame war die Mutter der jüngern, und auch sie besaß die vornehmsten Formen. Ihr Auge verriet einen krankhaft schwärmerischen Tiefsinn, um ihren Mund lag strenge Frömmigkeit, doch schien mir's, als ob er einst sehr schön gewesen sei, und viel gelacht und viele Küsse empfangen und viele erwidert habe. Ihr Gesicht glich einem Codex palimpsestus, wo unter der neuschwarzen Mönchsschrift eines Kirchenvatertextes die halberloschenen Verse eines altgriechischen Liebesdichters hervorlauschen. (DHA 6: 119)

Heine descubre este recuerdo de religiones antiguas que esconden los viejos mitos en superstición popular y en sus sagas, cuentos y baladas.

En los Cuadros de Viaje el autor remite a menudo a la mitología grecorromana, pero también a la popular, a las creencias en seres mágicos, una tradición que los románticos alemanes habían renovado. También tiene cabida el idilio, en escenas que respiran tranquilidad y armonía con la naturaleza. Lo mítico se junta con lo idílico y conforma así la imagen ideal del pueblo alemán. Heine cree con fervor en la realidad de la poesía llamada nacional, natural o popular. Le entusiasman la colección de canciones populares y antologías, Des Knaben Wunderhorn, y Die Volksliedsammlung. Sin embargo, Heine reprocha a los románticos su idealización de los tiempos pasados cuando él pretende tratar estos temas de forma crítica para integrarlos en los tiempos modernos. Y en su obra tardía, Heine se propone «desmitificar los mitos establecidos donde los hubiera, recreando una especial y personalísima mitología helénica e histórica» (Balzer 1995: 33). Se hace valer de los tropos para ironizar y parodiarlos. Heine cuenta en su Romancero una anécdota personal de cómo «en su última visita al Louvre, en febrero de 1848, se desplomó precisamente ante la Venus de Milo, su ideal de belleza sensual» (Balzer 1995: 33).

Nur mit Mühe schleppte ich mich bis zum Louvre, und ich brach fast zusammen, als ich in den erhabenen Saal trat, wo die hochgebenedeite Göttin der Schönheit, Unsere liebe Frau von Milo, auf ihrem Postamente steht. Zu ihren Füßen lag ich lange und ich weinte so heftig, daß sich dessen ein Stein erbarmen mußte. Auch schaute die Göttin mitleidig auf mich herab, doch zugleich so trostlos als wollte sie sagen: siehst du denn nicht, daß ich keine Arme habe und also nicht helfen kann? (DHA 3/1: 181)

Una de las características de Heine es que combina la mitología grecorromana con la nórdica y germánica recreando de ambas fuentes su propia poesía y reflexiona sobre ella (Häntzschel 2007: 191).

\section{LAS REFERENCIAS MITOLÓGICAS EN HARZREISE}

En este relato, el poeta parte del imaginario clásico grecorromano cuando nos sitúa en el mundo académico de la ciudad universitaria de Gotinga. Las figuras, como Apolo, Venus o Paris o personas mitificadas como Prometeo remiten al mundo universitario y académico. Las esculturas referenciadas aportan al narrador serenidad y disfrute de la belleza sensorial. 
A continuación, el narrador ya nos lleva de viaje y nos adentramos en el mundo mágico de los bosques y montañas y los lugares habitados por el «pueblo» que dan lugar a leyendas y cuentos protagonizados por duendes y elfos y donde las cosas cobran vida, hablan y tienen sentimientos.

\subsection{Primer sueño: En la biblioteca universitaria}

Como hemos dicho, podemos encontrar numerosas referencias a la mitología clásica grecorromana como Apolo, Venus o Paris, o personas mitificadas como Prometeo. Cuando Heine emplea este tipo de referencias clásicas, remite al mundo universitario y académico. Las figuras, sobre todo en forma de esculturas, aportan al narrador serenidad y disfrute de la belleza sensorial.

En los sueños del Harzreise el narrador procesa las vivencias del día anterior desfigurándolas. En la primera noche llega a Osterode. Está muy cansado y se acuesta sin cenar. Soñando vuelve a Gotinga y a la biblioteca de la Universidad. En la sala jurídica de la biblioteca aparece Themis, la diosa griega del Derecho, acompañada por los profesores de la Facultad de Historia del Derecho.

Ich stand in einer Ecke des juristischen Saals, durchstöberte alte Dissertationen, [...]. Die nahe Kirchenglocke schlug eben zwölf, die Saaltüre öffnete sich langsam, und herein trat eine stolze, gigantische Frau, ehrfurchtsvoll begleitet von den Mitgliedern und Anhängern der juristischen Fakultät. Das Riesenweib, obgleich schon bejahrt, trug dennoch im Antlitz die Züge einer strengen Schönheit, jeder ihrer Blicke verriet die hohe Titanin, die gewaltige Themis. Schwert und Wage hielt sie nachlässig zusammen in der einen Hand, in der andern hielt sie eine Pergamentrolle, zwei junge Doctores juris trugen die Schleppe ihres grau verblichenen Gewandes; an ihrer rechten Seite sprang windig hin und her der dünne Hofrath Rusticus, der Lykurg Hannovers, und deklamierte aus seinem neuen Gesetzentwurf; [...]. (DHA 6: 87)

Siguen entrando más docentes a los que el narrador tacha de insignificantes y poco a poco va aumentando el nivel de ruido por el parloteo y griterío de estos hasta que la diosa se impacienta y grita con desesperación:

»Schweigt! schweigt! ich höre die Stimme des teuren Prometheus, die höhnende Kraft und die stumme Gewalt schmieden den Schuldlosen an den Marterfelsen, und all euer Geschwätz und Gezänke kann seine Wunden nicht kühlen und seine Fesseln zerbrechen!« (DHA 6: 89)

Heine evoca aquí, en un primer plano de significación, la mitología clásica y la leyenda de Prometeo que, por haber robado el fuego a los dioses para ayudar a los hombres es encadenado por órdenes de Zeus a una roca y condenado a que un águila cada día le devore el hígado. Con los dos sintagmas siguientes Heine alude a las figuras de la tragedia de Esquilo, a su vez personajes alegóricos: die höhnende Kraft remite a Cratos (la Fuerza) y die stumme Gewalt a Bia (la Violencia), que aparece muda, según la tragedia, los dos encargados de encadenar a Prometeo a la roca. Esta alegoría le vale a Heine 
para que, en el segundo plano de significación, remita a Napoleón y le presente como benefactor de los hombres, prisionero en la isla de Santa Elena por culpa de los poderes de la Santa Alianza en la Alemania de la Restauración (DHA 6: 598). Napoleón, que llevó a los hombres la cultura jurídica, se halla encadenado a una roca. Heine explica en Reise von München nach Genua que se trata aquí de una referencia al emperador francés:

\begin{abstract}
Vielleicht nach Jahrtausenden, wird ein spitzfindiger Schulmeister in einer grundgelehrten Dissertation unumstößlich beweisen: dass der Napoleon Bonaparte ganz identisch sei mit jenem anderen Titane, der den Göttern das Licht raubte und für dieses Vergehen auf einem einsamen Felsen, mitten im Meere, angeschmiedet wurde. (Cap. XXVIII DHA 7/1: 67)
\end{abstract}

Y en la versión francesa del Harzreise de 1856 lo expone más explícitamente: «La forcé insultante et la violence muette de la sainte Alliance ont enchainé le héros sur un rocher dans l'Océan» (DHA 6: 598). Así queda claro que se refiere al emperador admirado por Heine, al que la Santa Alianza había recluido en 1815 en la isla Santa Elena. Pero se podría postular que la figura de Prometeo le sirve incluso como identificación consigo mismo (Park 2005: 150).

Después del caos que se desencadena en la biblioteca tras el ataque de pánico de la titana, el narrador se refugia en sueños en otra sala, buscando a «jener Gnadenstelle, wo die heiligen Bilder des belvederischen Apolls und der mediceischen Venus neben einander stehen», representaciones divinas de la poesía y del amor sensual:

[...] und ich stürzte zu den Füßen der Schönheitsgöttin, in ihrem Anblick vergaß ich all das wüste Treiben, dem ich entronnen, meine Augen tranken entzückt das Ebenmaß und die ewige Lieblichkeit ihres hochgebenedeiten Leibes, griechische Ruhe zog durch meine Seele, und über mein Haupt, wie himmlischen Segen, goß seine süßesten Lyraklänge Phöbus Apollo. (DHA 6: 89)

La reclusión de Napoleón en Santa Elena es para Heine la catástrofe histórica que queda simbolizada en el derrumbe de la sala jurídica. Y los dioses de la mitología clásica a los que recurre en la sala histórica representan la salvación para esta hecatombe. La sátira del mundo de la ciencia se dirige claramente a la jurisprudencia y sus representantes de Gotinga que Heine conocía personalmente. Enlaza los dos motivos populares del romanticismo negro, es decir, la aparición de fantasmas y las tinieblas de la medianoche recreando una escalofriante procesión de la ciencia cuyo escenario es la biblioteca universitaria de aquella ciudad (Guzu 2001: 315-316).

\title{
4.2 Segundo día: Visitando a la gente humilde de las minas
}

Al día siguiente, el narrador prosigue el viaje a Clausthal donde desciende a las minas de plata y describe la vida dura de la población minera. Cuando visita a la gente humilde en sus cabañas, Heine recurre a menudo al imaginario 
popular, a leyendas de los montes y a espíritus naturales. La naturaleza es uno de los temas importantes del Harzreise. Para el narrador mismo tiene en un principio una función terapéutica, la visión de la naturaleza le tranquiliza y sosiega.

[...] Die Berge wurden hier noch steiler, die Tannenwälder wogten unten wie ein grünes Meer, und am blauen Himmel oben schifften die weisen Wolken. [...] Wie ein guter Dichter liebt die Natur keine schroffen Übergänge. Die Wolken, so bizarr gestaltet sie auch zuweilen erscheinen, tragen ein weißes oder doch ein mildes, mit dem blauen Himmel und der grünen Erde harmonisch korrespondierendes Kolorit, so daß alle Farben einer Gegend wie leise Musik in einander schmelzen, und jeder Naturanblick krampfstillend und gemütberuhigend wirkt. (DHA 6: 91)

Pero va más allá, porque la identifica también como lugar en el que se pueden encontrar aun los restos del «pueblo» auténtico.

Das Volk hat noch immer den traditionell fabelhaften Ideengang, der sich so lieblich ausspricht in seinem «Herzog Ernst». (DHA 6: 90)

Se trata de reminiscencias a la idea romántica del pueblo como la expresa Joseph Görres en Die teutschen Volksbücher (1807) (DHA 6: 604), que Heine contrasta con la vida académica rancia y antinatural.

So stillstehend und ruhig auch das Leben dieser Leute erscheint, so ist es dennoch ein wahrhaftes, lebendiges Leben. Die steinalte, zitternde Frau, die dem großen Schranke gegenüber, hinterm Ofen saß, mag dort schon ein Vierteljahrhundert gesessen haben, und ihr Denken und Fühlen ist gewiß innig verwachsen mit allen Ecken dieses Ofens und allen Schnitzeleien dieses Schrankes. Und Schrank und Ofen leben, denn ein Mensch hat ihnen einen Teil seiner Seele eingeflößt. (DHA 6: 96)

En esta vida auténtica, la naturaleza adquiere rasgos antropomorfos y los habitantes de las zonas rurales tienen un vínculo y una comunicación especial con ella. Al principio del día, el narrador se encuentra con un niño que habla con pájaros y árboles y recibe respuesta de ellos. Se trata aquí de una imagen idealizada de la inocencia natural:

Die Kinder, dacht' ich, sind jünger als wir, können sich noch erinnern, wie sie ebenfalls Bäume und Vögel waren, und sind also noch im Stande, dieselben zu verstehen. (DHA 6: 91)

Lo que caracteriza la relación de esta gente con la naturaleza es su inmediatez:

Nur durch solch tiefes Anschauungsleben, durch die "Unmittelbarkeit" entstand die deutsche Märchenfabel, deren Eigentümlichkeit darin besteht, daß nicht nur die Tiere und Pflanzen, sondern auch ganz leblos scheinende Gegenstände sprechen und handeln. Sinnigem, harmlosen Volke in der stillen, umfriedeten Heimlichkeit seiner niedern Bergoder Waldhütten offenbarte sich das innere Leben solcher Gegenstände [...] und so sehen wir im Märchen, wunderbar und doch als wenn es sich von selbst verstände: Nähnadel 
und Stecknadel kommen von der Schneiderherberge und verirren sich im Dunkeln; Strohhalm und Kohle wollen über den Bach setzen und verunglücken; Schippe und Besen stehen auf der Treppe und zanken und schmeißen sich; der befragte Spiegel zeigt das Bild der schönsten Frau; sogar die Blutstropfen fangen an zu sprechen, bange dunkle Worte des besorglichsten Mitleids. (DHA 6: 96)

Todos los motivos insertados en este pasaje son cosas personificadas, un recurso muy típico de los cuentos, en este caso, de los Kinder- und Hausmärchen de los hermanos Grimm. Pero esta relación especial de la gente humilde con el medio que la rodea se está extinguiendo y únicamente la vivimos en la infancia:

Aus demselben Grunde ist unser Leben in der Kindheit so unendlich bedeutend, in jener Zeit ist uns alles gleich wichtig, wir hören alles, wir sehen alles [...] jetzt sind wir ausgewachsene, vornehme Leute; wir beziehen oft neue Wohnungen, die Magd räumt täglich auf, [...]. (DHA 6: 96-97)

El sueño de esa misma noche es de carácter poético-erótico que termina en pesadilla. Un caballero desciende a un pozo, lucha con enanos y despierta con un beso a una bella princesa. Se trata de claras referencias a los conocidos motivos de cuentos de hadas, pero también se puede interpretar como una descripción cifrada del intento de liberar al pueblo alemán (Winkler 1995: 112). Finalmente, el caballero se convierte en arlequín, en el que el narrador se reconoce a sí mismo, y tiene que huir espantado.

Es war das alte Märchen, wie ein Ritter hinabsteigt in einen tiefen Brunnen, wo unten die schönste Prinzessin zu einem starren Zauberschlafe verwünscht ist. Ich selbst war der Ritter, und der Brunnen die dunkle Klausthaler Grube, und plötzlich erschienen viele Lichter, aus allen Seitenlöchern stürzten die wachsamen Zwerglein, schnitten zornige Gesichter, hieben nach mir mit ihren kurzen Schwerten, [...]. [...] und ich gelangte in einen hellen Prachtsaal; in der Mitte stand, weiß verschleiert, und wie eine Bildsäule starr und regungslos, die Herzgeliebte, und ich küßte ihren Mund, [...] aber in demselben Augenblick wurde es wieder Nacht, und alles rann chaotisch zusammen in ein wildes, wüstes Meer. [...] über das gärende Wasser jagten ängstlich die Gespenster der Verstorbenen, ihre weißen Totenhemden flatterten im Winde, hinter ihnen her, hetzend mit klatschender Peitsche lief ein buntscheckiger Harlekin, und dieser war ich selbst [...]. (DHA 6: 98)

\subsection{Quinto día: Andando por el bosque}

Mientras el narrador camina por el bosque hacia el monte Brocken, se adentra cada vez más en la naturaleza. Los animales del bosque son criaturas que le merecen admiración y Heine tenía una opinión muy crítica sobre la caza, ya expresada en Nordsee III.

Auf den Zweigen der Tannen kletterten Eichhörnchen und unter denselben spazierten die gelben Hirsche. Wenn ich solch ein liebes, edles Tier sehe, so kann ich nicht begreifen, wie gebildete Leute Vergnügen daran finden, es zu hetzen und zu töten. Solch ein Tier war barmherziger als die Menschen und säugte den schmachtenden Schmerzenreich der heiligen Genoveva. (DHA 6: 114-15) 
Heine remite aquí a la antigua leyenda cristiana según la cual la hija del duque de Brabante fue acusada de adulterio y desterrada por su marido para vivir durante seis años en el bosque, donde una cierva amamantó a su hijo Schmerzenreich. Tieck publicó en 1799 una adaptación dramática de la leyenda, aunque Heine prefería la versión de un Volksbuch antiguo como indica en Die Romantische Schule (DHA 6: 614).

En la medida en que avanza le invaden pensamientos románticos e idealizadores y todo cobra vida misteriosa:

\begin{abstract}
Allerliebst schossen die goldenen Sonnenlichter durch das dichte Tannengrün. [...] Wenn man sich nach diesem Treiben hinabbeugt, so belauscht man gleichsam die geheime Bildungsgeschichte der Pflanzen und das ruhige Herzklopfen des Berges. [...] Es murmelt und rauscht so wunderbar, die Vögel singen abgebrochene Sehnsuchtslaute, die Bäume flüstern wie mit tausend Mädchenzungen, wie mit tausend Mädchenaugen schauen uns an die seltsamen Bergblumen, [...]. [...] die sinnigen Kräutlein erzählen sich grüne Märchen, es ist alles wie verzaubert, es wird immer heimlicher und heimlicher, ein uralter Traum wird lebendig, die Geliebte erscheint - [...]. (DHA 6: 115)
\end{abstract}

De nuevo, vemos como la naturaleza adquiere significado simbólico en Heine y remite a tiempos remotos y mundos encantados.

\title{
4.4. Sexto día: Volviendo del monte Brocken
}

El quinto día narra el viaje hacia el Brocken, la mítica montaña del Blocksberg, en la que se celebra el aquelarre de brujas durante la noche de Walpurgis en el Faust de Goethe. En la casa del Brocken, se encuentra con dos damas hermosas y los demás huéspedes, en su práctica totalidad, son miembros de asociaciones estudiantiles y también algunos jóvenes exaltados y sentimentalistas. Somos testigos de una juerga de estudiantes de ideología nacionalista que se emborrachan contando disparates y episodios con falsos románticos. Por la noche, el narrador vive otra pesadilla en la que se le aparecen nuevamente personajes de Gotinga e imágenes angustiosas («ein Klavierauszug aus Dantes Hölle», DHA 6: 127).

Amanece el sexto y último día y el narrador presencia juntamente con los demás huéspedes la salida del sol en el Brocken y emprende la bajada. Pasa por el valle del río Ilse y la vivencia en la naturaleza vuelve a ser mágica y sensual.

Es ist unbeschreibbar, mit welcher Fröhlichkeit, Naivität und Anmut die Ilse sich hinunterstürzt über die abenteuerlich gebildeten Felsstücke, [...] Ja, die Sage ist wahr, die Ilse ist eine Prinzessin, die lachend und blühend den Berg hinabläuft. Wie blinkt im Sonnenschein ihr weißes Schaumgewand! Wie flattern im Winde ihre silbernen Busenbänder! (DHA 6: 131-132)

El narrador canta a la princesa Ilse y se repiten los motivos de noviazgo y vida palaciega como en el poema del Bergidylle y en general, las metáforas de juventud y matrimonio: 
Ich bin die Prinzessin Ilse,

Und wohne im Ilsenstein

Komm mit nach meinem Schlosse

Wir wollen selig sein.

Dein Haupt will ich benetzen

Mit meiner klaren Well',

Du sollst deine Schmerzen vergessen,

Du sorgenkranker Gesell!

In meinen weißen Armen,

An meiner weißen Brust,

Da sollst du liegen und träumen

Von alter Märchenlust. (DHA 6: 132-133)

Las metáforas relacionadas con los ríos se asemejan a las que emplea Goethe en Mahomets Gesang (DHA 6: 632). Cuando el narrador prosigue su viaje atraviesa los tres valles del Bajo Harz que se forman en torno a los ríos Ilse, Bode y Selke. Personifica el carácter de cada uno de estos ríos y se ve delante de tres mujeres de entre las cuales no le es nada fácil decidir cuál es la más hermosa.

Die düstere Schöne die Bode, empfing mich nicht so gnädig, und als ich sie im schmiededunkeln Rübeland zuerst erblickte, schien sie gar mürrisch, und verhüllte sich in einen silbergrauen Regenschleier. Aber mit rascher Liebe warf sie ihn ab, als ich auf die Höhe der Roßtrappe gelangte, ihr Antlitz leuchtete mir entgegen in sonnigster Pracht, aus allen Zügen hauchte eine kolossale Zärtlichkeit. (DHA 6: 135)

La segunda de las mujeres-río es Selke que se caracteriza por su carácter más bromista:

[...] die schöne Selke, die schöne, liebenswürdige Dame, deren edle Einfalt und heitere Ruhe alle sentimentale Familiarität entfernt hält, die aber doch durch ein halbverstecktes Lächeln ihren neckenden Sinn verrät; [...]. Und jetzt steht sie vor meiner Einbildung mit all ihrem stillen Liebreiz, und scheint zu sagen: Wenn ich auch lache, so meine ich es doch gut mit Ihnen, und ich bitte sie, besingen Sie mich! (DHA 6: 135)

Pero entre las tres, Bode, Selke e Ilse, prefiere a esta última:

Auch die schöne Ilse kommt herangesprungen, zierlich und bezaubernd in Miene, Gestalt und Bewegung; sie gleicht ganz dem holden Wesen, das meine Träume beseligt, und ganz, wie Sie, schaut sie mich an, mit unwiderstehlicher Gleichgültigkeit und doch zugleich so innig, so ewig, so durchsichtig wahr. - Nun, ich bin Paris, die drei Göttinnen stehen vor mir, und den Apfel gebe ich der schönen Ilse. (DHA 6: 136)

Heine cierra aquí el círculo y tras pasar por el mundo natural personificado vuelve a las metáforas de la mitología clásica y, con ello, a la serenidad. 


\section{CONCLUSIONES}

Las referencias mitológicas forman parte del estilo particular de Heine. Junto con el resto de referencias intertextuales dibujan un mundo referencial muy específico, en el que podemos observar una mezcla de figuras literarias procedentes de imaginarios diversos, la mitología clásica y la mitología popular, con raíces germánicas y medievales, así como la tradición romántica de los cuentos infantiles con fuerte arraigo en los motivos ligados a la naturaleza. Contribuyen a crear un mundo florido y mágico que sirve de refugio para un autor desgarrado en su identidad y ansioso por encontrar un hogar en un mundo hostil. Este refugio es a la vez amenazado por el mundo universitario filisteo y retrógrado y la situación política adversa del pre-marzo alemán. Heine se sirve de estas herramientas estilísticas para remitir con las referencias greco-latinas a un acervo compartido culto, y con las referencias a la mitología popular expresa su nostalgia por un mundo perdido lleno de supuesta inocencia y naturalidad y más próximo al «pueblo».

Aunque en su obra tardía emplea las referencias al mundo mitológico con claro distanciamiento que se expresará sobre todo en Die Götter im Exil, en su obra temprana, remite a menudo a los mundos míticos y mágicos con el fin primordial de recrear una sensualidad y estética que no encuentra en otros imaginarios. El trato de la naturaleza en Harzreise muestra un lado pesimista en Heine que se expresa en la visión utilitarista e ilusoria por parte de muchos de sus personajes que intentan huir de la realidad, y al final, la naturaleza se muestra como decorado, como vida artificial. A pesar de ello, la recreación de la naturaleza en su expresión sumamente afectiva que encontramos en Harzreise es sin duda el reflejo poético de la esperanza real de emancipación (Kortländer 2003: 164) en el pre-marzo alemán que cual leitmotiv planea sobre el proyecto global de los Reisebilder.

\section{BIBLIOGRAFÍA}

BALZER, B. (1995), Heinrich Heine. Gedichte-Auswahl. Antología poética, Madrid, Ediciones de la Torre.

BOERnER, M.-C. (2003), «'Je ne fais que rêver Italie'. Heinrich Heines Verfahren der Fiktionalisierung in den italienischen Reisebildern», Germanisch-Romanische Monatsschrift, GRM 53, 205-220.

DHA = HEINE, H. (1973 y ss.), Historisch-kritische Gesamtausgabe der Werke (Düsseldorfer Heine-Ausgabe DHA), Windfuhr, M. (ed.), Hamburg, Hoffmann und Campe.

GuZU, M. (2001), «Nachtgesichte der 'Harzreise': zur bewussten Wiedergabe authentischer Traumstrukturen in Heines Traumerzählungen», Zeitschrift der Germanisten Rumäniens, 10(1), 315-321.

HÄNTZSCHEL, G. (2007), «Nordische und antike Mythologie bei Heinrich Heine», en Nördlichkeit - Romantik - Erhabenheit, Fülberth, A., Meier, A. y Ferretti, V. A., Frankfurt am Main, Peter Lang, 191-202. 
HeINE, H. (2003), Cuadros de viaje, Introducción, traducción y notas por Isabel García Adánez, Madrid, Gredos.

HeIne, H. (2008), Die Harzreise, Liedtke, Ch. (ed.), Hamburg, Hoffmann und Campe. HÖHN, G. (2004³), Heine-Handbuch: Zeit, Person, Werk, Stuttgart, Metzler.

KIRCHER, H. (2016), «Heinrich Heine», Goethezeitportal. Disponible en: http://www.goethezeitportal.de/fileadmin/PDF/db/wiss/heine/kircher_heine.pdf.

KORTLÄNDER, B. (2003), Heinrich Heine, Ditzingen, Reclam.

PARK, E. K. (2005). ... meine liebe Freude an dem Göttergesindel: Die antike Mythologie im Werk Heinrich Heines, Stuttgart y Weimar, Metzler.

WINKLER, M. (1995), Mythisches Denken zwischen Romantik und Realismus. Zur Erfahrung kultureller Fremdheit im Werk Heinrich Heines, Tubinga, Niemeyer. 